\title{
НАЗНАЧЕНИЕ ИНФОРМАЦИОННЫХ И СМАРТ-ТЕХНОЛОГИЙ В ОБРАЗОВАНИИ И ИХ ВЛИЯНИЕ НА КОММУНИКАТИВНЫЕ ХАРАКТЕРИСТИКИ ЛИЧНОСТИ
}

\author{
Боева А.Ю., Чуева М.Ю.
}

ФГБОУ ВО Московский Государственный Университет Технологий и Управления им. К.Г. Разумовского (ПКУ), г. Москва, Российская Федерация

Рассмотрен вопрос положстельного и отрицательного влияния использования информационных технологий в образовательном процессе, который влечет ответственность преподавателя и родителя по отношению к учащемуся, рассмотрено влияние информационного пространства на психические паттерны учашихся.

Ключевые слова: информационные технологии; Смарт-технологий; образование; коммуникативные характеристики личности.

\section{THE PURPOSE OF INFORMATION AND SMART-TECHNOLOGIES IN EDUCATION AND THEIR IMPACT ON THE COMMUNICATIVE CHARACTERISTICS OF THE INDIVIDUAL}

Boеva A. Yu., Chueva M.Yu.

K.G. Razumovsky Moscow State University of technologies and management (the First Cossack University), Moscow, Russian Federation

The question of positive and negative impact of the use of information technology in the educational process, which entails the responsibility of the teacher and the parent in relation to the student, the influence of the information space on the mental patterns of students. 
Keywords: information technologies; Smart technologies; education; communicative characteristics of personality.

В XXI веке представить свою жизнь без интерактивного устройства не возможно, вся твоя жизнь в одном устройстве. Много пишется о том как положительно влияют информационные технологии на обучаемость учащихся, и так же много пишут о негативном влиянии информационных технологий. Хотелось бы разобраться с этим актуальным вопросом информационные технологии это хорошо или нет.

Для начала проанализируем исследовательские работы уважаемых членов Российской Академии Образования о современных информационных технологий и их влиянии на коммуникативные характеристики личности. Рассмотрим среднестатистического молодого человека в возрасте от 18-30 лет.

Установлено, что в настоящее время язык становится все более онтологическим (систематизирующем) и менее семиотическим (философским) или эпистемологическим. Онтологический режим общения вытесняет функции смысла слова, смысла вещей, что является новым типом глобальных коммуникаций.

На просторах интернета коммуникационное поведение личности в значительной степени отличается от коммуникативного поведения от реального общения. Констатируется, что ухудшается нравственные и интеллектуальные качества личности. Причиной этого является особенности масскультуры, транслируемые через СМИ, которые в свою очередь, обесценивают стереотипы образного мышления и эмоциональных паттернов нашей личности.

Стандартные жизненные ситуации, становятся унифицированными из-за увеличения темпа жизни и сопровождающего его прогрессирующим дефицитом времени.

«Выявлено, что речевой портрет современника существенно изменился, прежде всего, в сторону агрессивности его общения: все больше в коммуникативном взаимодействии молодых людей доминируют стереотипы, ориентированные на оскорбление, унижение, демонстративную индентифирентность в высказываниях другого 
человека, и все меньше имеет место ориентация на объяснения, дискуссию, совет, просьбу, выражения сочувствия, уважения, симпатию. Также установлено, что в сети интернет отсутствует ориентация на стандарты формально-делового общения, характерные для деловых отношений» [3].

Статистика показывает, что в России страдает 15,5 млн жителей тяжелыми глазными заболеваниями, и все чаще ставится диагноз «компьютерный зрительный синдром», также наряду с этим ставятся диагнозы относительно заболеваний позвоночника и нервные, психические заболевания.

Негативных факторов множество, но компьютерный этап начался и он неотвратим. Но все эти рассмотренные мною ранее факторы касались в основном домашнего использования интерактивных устройств, бесконтрольное его использование влечет, к сожалению, много опасностей.

Что касается применения в образовании новых технологий, то умеренное его использование или использование приемов интерактивных уроков повышает концентрацию вниманию и задействует запоминательные, психические процессы мозга учащихся. Основными каналами восприятия информации являются:

Звуковой канал. Исследования показали, что человек лишенный шумов менее активен и ощущает психологический дискомфорт, а при постоянном музыкальном фоне работоспособность учащихся повышается в среднем примерно на 20\%. «Поэтому в учебном процессе нужно предусматривать, как минимум, четыре мелодии разных типов. Упорядоченные периодические и разовые сигналы, вроде телефонных звонков, звука будильника, привлекающего внимания писка, поощрительно-приятных или наказывающе-неприятных звуков играют, обычно, отвлекающую, мобилизующую, информативную и редко нейтральную роль. Целенаправленное и систематическое использование таких сигналов может быть полезным дополнением в системе звуковых воздействий на ученика» [2].

Кинестетический канал (использование микрофона, наборы лего и так далее). 
Визуальный канал. «Так, первичное обследование объекта осуществляется с помощью многочисленных движений глаз. После того как объект исследован, внимание к нему ослабевает. В дальнейшем человек реагирует только на изменения, происходящие с объектом или в объекте. При этом, на движущиеся объекты реакция у человека более сильная, чем на неподвижные. На приближающиеся или удаляющиеся объекты наблюдается более сильная реакция, чем на просто движущиеся. Поэтому при проектировании занятий следует отдавать предпочтение тем приемам обучения, где используются движущиеся объекты, причем в первую очередь - приближающимся или удаляющимся объектам, затем объектам, проходящим мимо глаза и, наконец, изменяющимся со временем объектам» [2].

Современные тенденции информатизировать образование должны сопровождаться методологическими методами, которые инициирует совершенствование базы научных данных, управление системой образования, выбор новых стратегий, новых методов и методологий ведения уроков, инклюзивного образования, ориентация на индивидуальные способности учащихся, выбор самостоятельной работы учащихся и обеспечение их рефлексии, разработку новых систем контроля успеваемости.

В течении 5 лет число детей, умеющих пользоваться компьютером, увеличилось примерно в 10 раз, эта тенденция будет ускоряться независимо от школьного образования, но дети знакомы в основном с игровыми компьютерными программами, используют компьютерную технику для развлечения, и мотивы использования компьютера для образовательного процесса стоят на двадцатом месте.

К огромному сожалению можно констатировать, что на данный момент в целом по стране многие учителя не обладают компьютерной грамотностью или их уровень не достаточен для проектирования интересного увлекательного урока.

В основном ИТ применяются для дистанционного образования и для наглядного уточнения уже имеющейся информации. Для того чтобы учителя могли выводить компьютерные технологии на новый уровень необходимо повышение квалификации, не то где просто 
расскажут какие методы существуют, повышение квалификации с практикой минимум в три месяца, где людей спровоцируют к рефлексии о том как правильно должен быть построен процесс

Эффективность применения ИТ в образовании обусловлена следующими факторами: высокая степень наглядности, многообразие представления информации; организация оперативного контроля, моделирование процессов, возможность дифференцированного подхода к работе учащихся, возможность организации коллективной исследовательской работы.

Роберт И.В. и Самойленко П.И. в своей работе, рассматривали классификацию информационных и коммуникационных технологий по способу их использования, как средство обучения; средство, совершенствующих процесс преподавания; инструмент познания окружающей действительности и самопознания; средство развития личности обучаемого; объект изучения в рамках освоения курса информатики; средство коммуникаций; средство автоматизации процесса обработки результатов эксперимента и управления; средство автоматизации процессов контроля и коррекции результатов учебной деятельности, тестирования и психодиагностики; средство организации интеллектуального досуга.

Назначение СМАРТ-технологий - это объединение учебных заведений и профессорско-преподавательского состава для осуществления совместной образовательной деятельности в сети Интернет на базе общих стандартов, соглашений и технологий».

Smart-образование включает в себя накопленные и выработанные подходы к обучению в традиционном их понимании с элементами дистанционного обучения с использованием информационно-телекоммуникационных технологий (ИКТ). Концепция smart-образования предполагает комплексное развитие образовательной услуги, включая кадровое обеспечение, административно-правовое управление, материально-техническую базу и пр. То есть предполагается, в первую очередь, создание определенной среды (smart-среды), в которой всем участникам образовательного процесса будет комфортно взаимодействовать для достижения главной цели - получения качественного образования. 
Подводя итоги можно сделать следующие выводы:

1. Применение ИКТ благоприятно влияет на образовательный процесс, только при условии, что все дети в классе одного образовательного уровня;

2. Информационные технологии дают неограниченный доступ к информации и открывают возможности вариативности учебной деятельности, ее индивидуализации и дифференциации.

3. При помощи компьютера возможно сочетать разнообразные методы, экономит время урока, позволяет организовать процесс обучения по индивидуальным программам.

4. Компьютер способствует формированию у учащихся рефлексии своей деятельности, позволяет учащимся наглядно представить результат своих действий.

5. СМАРТ-технологии - это отличный вариант взаимодействия учащийся-преподаватель, которые не зависят от времени и местоположения, что способствует экономии времени, что решает задачу мегаполисов «дефицита времени».

6. Так же огромная ответственность лежит на родителях, которые бесконтрольно приобретают своим чадам интерактивные устройства. Взаимодействие родитель - школа-ученик - этот процесс необходимо усовершенствовать.

7. Так же на законодательном уровне отрегулировать использование гаджетов несовершеннолетними детьми.

\section{Список литературы}

1. Васецкая Н.О., Глухов В.В. Научно-технические ведомости СПбГПУ. Экономические науки. Том 10, № 5, 2017. Смарт-обучение в системе повышения профессиональной подготовки.

2. Беспалько В.П. Образование и обучение с участием компьютеров.М.: Изд-во Московского психолого-социального института; Воронеж: Изд-во НПО “МОДЕК”,2010. 352 с.

3. Берулава Г.А. Влияние современных информационных технологий на коммуникативные характеристики личности. Гуманизация образования. 2013. №6. С. 10-15. 
4. Бухаркина М.Ю. Формирование школьного информационного пространства на основе современных ИТ. единой информационной образовательной среды. - «Кирилл и Мефодий».

5. Варфоломеева Т.Н., Хуббитдинов 3.С. Влияние использования информационных технологий на деятельность педагогических субъектов. VII Международная студенческая научная конференция Студенческий научный форум - 2015.

6. Информатизация общего среднего образования: науч.-метод. пособие / Под ред. Д.Ш. Матроса. М.: Педагогическое общество России, 2009. 384 c.

7. Информационное пространство школы // Специальное приложение к журналу «Лицейское и гимназическое образование». М., 2008.

8. Левина М.М. Технологии профессионального педагогического образования: Уч. пособие для студ. высш. пед. зав. М.: Изд, центр “Академия”, 2007. 272 с.

9. Мухин О.И. Моделирование в обучении. География / О.И. Мухин // Информационные технологии в образовании: Материалы Всероссийской научной конференции [Электронный ресурс] - http://ito. edu.rU/2003/II/l/II-l-2927.html - статья в интернете.

10. Статистика министерства здравоохранения. https://www.rosminzdrav.ru/

\section{References}

1. Vasetskaya N.O., Glukhov V.V. Nauchno-tekhnicheskie vedomosti SPbGPU. Ekonomicheskie nauki. Tom 10, № 5, 2017. Smart-obuchenie v sisteme povysheniya professional'noy podgotovki.

2. Bespal'ko V.P. Obrazovanie i obuchenie s uchastiem komp'yuterov. M.: Izd-vo Moskovskogo psikhologo-sotsial'nogo instituta; Voronezh: Izdvo NPO "MODEK", 2010. 352 s.

3. Berulava G.A. Vliyanie sovremennykh informatsionnykh tekhnologiy na kommunikativnye kharakteristiki lichnosti. Gumanizatsiya obrazovaniya. 2013. №6, pp. 10-15.

4. Bukharkina M. Yu. Formirovanie shkol'nogo informatsionnogo prostranstva na osnove sovremennykh IT. edinoy informatsionnoy obrazovatel'noy sredy. «Kirill i Mefodiy» 
5. Varfolomeeva T.N., Khubbitdinov Z.S. Vliyanie ispol'zovaniya informatsionnykh tekhnologiy na deyatel'nost' pedagogicheskikh sub"ektov. VII Mezhdunarodnaya studencheskaya nauchnaya konferentsiya Studencheskiy nauchnyy forum -2015 .

6. Informatizatsiya obshchego srednego obrazovaniya: nauch.-metod. posobie / Pod red. D.Sh. Matrosa. M.: Pedagogicheskoe obshchestvo Rossii, 2009. $384 \mathrm{~s}$.

7. Informatsionnoe prostranstvo shkoly // Spetsial'noe prilozhenie k zhurnalu «Litseyskoe i gimnazicheskoe obrazovanie». M., 2008.

8. Levina M.M. Tekhnologii professional'nogo pedagogicheskogo obrazovaniya: Uch. posobie dlya stud. vyssh. ped. zav. M.: Izd, tsentr "Akademiya", 2007. $272 \mathrm{~s}$.

9. Mukhin O.I. Modelirovanie v obuchenii. Geografiya / O.I. Mukhin // Informatsionnye tekhnologii v obrazovanii: Materialy Vserossiyskoy nauchnoy konferentsii [Elektronnyy resurs] - http://ito.edu.rU/2003/II/1/ II-1-2927.html - stat'ya v internete.

10. Statistika ministerstva zdravookhraneniya. https://www.rosminzdrav.ru/ 